\title{
Potential Diagnostic Techniques for Cervical Cancer Prevention - Review
}

\author{
Igor M. A. Melo, Eliane A. Ribeiro, Renata A. Canevari*
}

Laboratório de Biologia Molecular do Câncer, Instituto de Pesquisa \& Desenvolvimento (IP\&D), Universidade do Vale do Paraíba (UNIVAP), São José dos Campos, São Paulo, Brasil

\section{Article Info}

\section{Article Notes}

Received: April 8, 2018

Accepted: November 17, 2018

\section{*Correspondence:}

Dr. Renata A. Canevari, Laboratório de Biologia Molecular do Câncer, Instituto de Pesquisa \& Desenvolvimento (IP\&D), Universidade do Vale do Paraíba (UNIVAP), São José dos Campos, São Paulo, Brasil; E-mail: rcanevari@univap.br.

(c) 2018 Canevari RA. This article is distributed under the terms of the Creative Commons Attribution 4.0 International License.

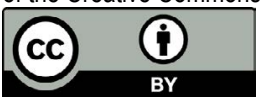

\section{Keywords}

Diagnosis

Cervical Cancer

HPV

Molecular Biology

Biomarkers

FTIR

\section{ABSTRACT}

Human papillomavirus (HPV) infection is the most common sexually transmitted disease worldwide and several studies have proven the close relationship between HPV and the development of cervical cancer. Several tests are currently performed for early and reliable diagnosis, in which the cervical cytology evaluation by the Papanicolaou method is highlighted. However, errors in the collection and misinterpretation of cell differentiation degree in smear by the pathologist result in incorrect or inaccurate results. Considering these points, it is of utmost importance to develop new technologies that perform accurate and reliable diagnosis and that present financial advantages and accessibility. Currently, molecular biology assays are excellent detectors of viral DNA, but it presents disadvantages, such as the need for high financial resources to gain access. Therefore, this review has the objective of highlighting the main diagnostic techniques that are already being used, such as specific kits for the detection of high-risk HPVs, or methodologies that are still in the study phase, but which already present good results, such as the application of physical FTIR spectroscopy principles and ultrasensitive biosensors.

\section{Introduction}

Cervical cancer is an important public health problem that deserves attention of the scientific community. The World Health Organization (WHO) has reported a general increase in the incidence of cervical cancer in recent years ${ }^{1}$, which is the fourth most common cancer worldwide among the female population. The incidence estimated by the GLOBOCAN database revealed about 528,000 new cases were diagnosed in 2012, with 266,000 deaths worldwide in this year².

Many diagnosis modalities enable the detection of precancerous lesions in their early stages like the conventional screening that includes colposcopy, cervical cytology by Papanicolaou test and biopsy ${ }^{3}$. The implementation of screening based on oncotic colpocitology significantly contributed to the declined of cervical cancer incidence and mortality (50 to $70 \%$ ) about 50 years ago ${ }^{4}$ because, through this technique, the pathologist visualize the degree of cell differentiation, what can guide the treatments and minimize the increase of invasive cervical cancers ${ }^{5}$. However, although this technique is the most commonly used test for diagnosing lesions that precede cervical cancer, this method exhibits falsenegative rates around 15 to $50 \%$, due to misinterpretation by the professional or inadequate collection ${ }^{6}$. Therefore, there is a need for the improvement of new effective diagnostic techniques that allow a more accurate and reliable prognosis.

Human Papillomavirus (HPV) is the main factor pointed in literature that is associated with the development of cancer in the 
uterine cervix. WHO indicates more than $99 \%$ of the cases of this malignancy are caused by HPV infection ${ }^{7}$, because the viral oncoproteins starts a disturbance on cell-cycle control, resulting on the carcinogenesis ${ }^{8}$. Besides cervical cancer, several studies have demonstrated the strong relationship between HPV and the development of others malignant tumors, as in oropharynx, anus, penis, vulva and cervix ${ }^{9}$. This reveals the biological relevance of HPV and the importance of the study of virus role on cell-cycle.

Currently, direct detection of the virus can be performed by molecular biology through nucleic acid tests for HPV. This set of techniques is highly sensitive and can specifically identify the presence of virus in the host, even in its latent state $^{4}$. The type discrimination of HPV in clinical materials from the genital mucosa is important since it is possible to identify whether it will form high or low-grade lesions for the development of cancer ${ }^{10}$. Therefore, HPV type analysis has the potential to assist in the conduct of a more appropriate treatment, avoiding more invasive procedures in the patient.

In conclusion, the disadvantages of conventional screening techniques suppose the need for additional diagnostic techniques that present greater sensitivity, specificity, act quickly at an affordable cost, such as nucleic acid hybridization assays, polymerase chain reaction techniques, microarray analysis, protein-based assays, the principles of FTIR spectroscopy and ultrasensitive biosensors. Some of them are already being studied and presented greater effectiveness in the diagnosis of HPV when compared with oncotic colpocitology, for example ${ }^{4}$.

\section{HPV}

All Human Papillomavirus has a common genome organization $^{11}$ with a small circular and double-stranded deoxyribonucleic acid (DNA), which contains approximately $8,000 \mathrm{bp}$ (base pairs) ${ }^{12}$. This genetic material is surrounded by an icosahedral protein capsid ${ }^{17}$ and is formed by the Long Control Region (LCR) and the Open Reading Form (ORF), which contains eight genes classified as "early" and "late", according the expression pattern ${ }^{13}$. Although the "early" region is composed by six genes, which encodes the proteins E1, E2, E4, E5, E6 and E7, the "late" region contain only two genes that's encoding the proteins L1 and L2 ${ }^{14}$. Furthermore, the LCR controls viral replication and transcription $^{15}$.

The genes E1, E2 and E5 are associated with the viral DNA replication and transcriptional regulation of viral oncogenes, while E4 is associated with the cellular keratin network ${ }^{16}$. E6 and E7 are oncogenes because of their ability to inhibit cell differentiation due to genomic instability arising from the expression of these genes ${ }^{17}$. The resulting proteins expressed by these oncogenes bind and inactivate important cell-cycle regulation proteins, such

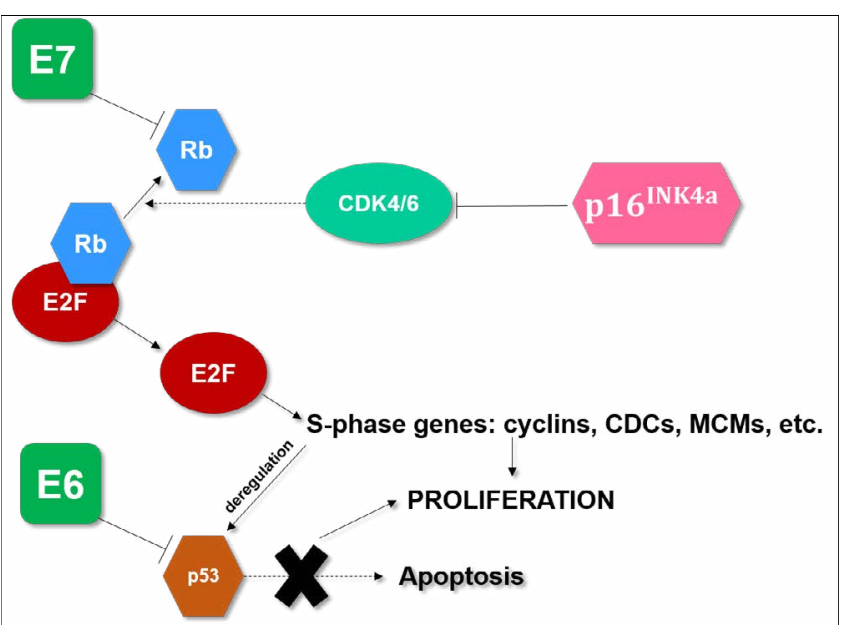

Figure 1: Interaction between viral oncogenes and cell cycle regulatory proteins. The human papillomavirus E6 and E7 oncoproteins have affinity for two important regulatory proteins, p53 and $\mathrm{Rb}$, respectively, and this ability does not allow these proteins to perform their correct functions. In normal conditions, $\mathrm{Rb}$ is a protein that does not allow activation of the E2F transcription factor, preventing the passage to the $S$ phase, while $p 16^{\text {INK4A }}$ is a tumor suppressor that blocks the phosphorylation of $\mathrm{Rb}$ through its binding to phosphorylating factors. When infected by HPV, E2F is activated due to the binding of E7 to $\mathrm{pRb}$. This binding causes the accumulation of phosphorylation factors and, consequently, the accumulation of p16 ${ }^{\text {INK4A }}$. Meanwhile, E6 binds to p53 and blocks cell cycle control and induction to apoptosis, which results in cell proliferation.

p53 and pRb (tumor suppressors), causing, consequently, an accumulation of $\mathrm{p} 16^{\mathrm{INK} 4 \mathrm{~A}}$ (a cyclin-dependent kinase inhibitor) in the infected cells (figure 01) ${ }^{18,19}$. The genes contained on "late" region have highly conserved sequences in all papillomaviruses and is associated with the formation of the capsid proteins ${ }^{20}$. This conservation makes possible to demarcate the L1 gene as a target for numerous molecular techniques ${ }^{21}$.

Until the present moment, more than 200 HPV types have been identified and classified into five phylogenetic genera: Alphapapillomaviruses, Betapapillomaviruses, Gammapapillomaviruses, Mupapillomaviruses and Nupapillomaviruses ${ }^{22}$. The mains parameters to define and establish a new HPV type is the nucleotide sequence of the L1 gene ${ }^{23}$. When HPV types have more than $60 \%$ of similarity, they belong to the same genera. However, only HPV types with less than $90 \%$ similarity are classified as new $^{24}$

Basically, HPV types are classified in two important groups based on oncogenic potential: the high-risk (HR) and low-risk (LR). The HR types, constituted by types 16, $18,31,33,35,39,45,51,52,56,58,59$, among others, are found in $99 \%$ of invasive cancer cases, like anogenital and oropharyngeal cancers, with types 16 and 18 being the most representative, which induce cervical lesions ${ }^{25}$. LR 
types are frequently associated to genital warts, laryngeal papilloma, respiratory papillomatosis and benign lesions and include some types like $6,11,40,42,43$ and $44^{16}$.

\section{Diagnosis techniques}

The detection of HPV by routine examination of women's health is important to cervical cancer prevention ${ }^{26}$. Therefore, virus genotyping and to know the proteins that the genome of this virus codifies, as well as its functions and interactions, is essential for identifying oncogenic types and providing more information about risk stratification or persistence of infection. Considering the importance of HPV detection and the influence of this virus in altering the expression and function of protein activity, several methods are being developed for these purposes, each presenting its advantages and disadvantages (Table 1).

\section{Nucleic Acid Hybridization Assays}

Nucleic acid hybridization assays, such as southern blotting, in situ hybridization, and dot-blot hybridization utilize radio-labeled nucleic acid hybridization to detect
HPV infection in cervical samples. Although these techniques generate high quality information, require many steps in order for the samples to be processed and the assay completed, need for large amounts DNA and time-consuming procedures, not being so convenient for routine diagnosis ${ }^{27}$.

The Digene ${ }^{\circledR}$ HPV test, which uses Hybrid Capture ${ }^{\circledR} 2$ (hc2) technology, and the Cervista ${ }^{\circledR}$ HPV HR assay are the only methods currently available to the US Food and Drug Administration (FDA) for diagnostic tests in the United States ${ }^{28}$. The Hybrid ${ }^{\circledR} 2$ system is a method used for signal amplification based on the hybridization of HPV target DNA with labeled RNA probes. This test distinguishes between the HR and LR groups and detects 13 HR-HPV types and 5 LR types, but it is not a sensitive for the genotyping of a single virus (51 type). The Cervista ${ }^{\circledR}$ HPV detects the presence of 14 high-risk types $(16,18,31,33,35,39,45$, $51,52,56,58,59,66$ and 68$)^{29}$. These assays showed lower false-positive rates and high sensitivity and specificity for HPV-16/18 genotyping ${ }^{30}$.

Table 1. Techniques used to detect Human Papillomavirus and to evaluate the risk of developing cervical cancer.

\begin{tabular}{|c|c|c|}
\hline Technique & Pros & Cons \\
\hline Screening based on colpocitology & $\begin{array}{l}\text { - allowed a drastic reduction in mortality } \\
\text { rates from cervical cancer worldwide. } \\
\text { detects tissue lesions and morphological } \\
\text { alterations of cells }\end{array}$ & $\begin{array}{l}\text { - depends of the professional's interpretation } \\
\text { and the quality in the material collection. } \\
\text { Exhibits false-negative rates around } 15 \% \text { - } \\
50 \% \text {. } \\
\text { - does not detect latent HPV infection. }\end{array}$ \\
\hline $\begin{array}{l}\text { Nucleic Acid Hybridization Assays } \\
\text { (Southern Blotting, in situ hybridiza- } \\
\text { tion and dot-blot hybridization) }\end{array}$ & $\begin{array}{l}\text { - } \quad \text { high quality information } \\
\text { - } \begin{array}{l}\text { distingue between the HR and LR HPV } \\
\text { types }\end{array}\end{array}$ & $\begin{array}{l}\text { - } \text { require many steps for the processing of } \\
\text { samples } \\
\text { - } \quad \text { risk of contamination }\end{array}$ \\
\hline $\begin{array}{l}\text { Polymerase chain reaction techniques } \\
\text { (HPV-PCR, PCR-RFLP, multiplex PCR, } \\
\text { RT-qPCR) }\end{array}$ & $\begin{array}{l}\text { - } \quad \text { high capacity to detect viral load } \\
\text { - } \quad \text { evaluation of oncogenes expression }\end{array}$ & $\begin{array}{l}\text { - } \quad \text { False-negative results for multiple type infec- } \\
\text { - } \quad \text { rions and samples with low copy numbers } \\
\text { - } \quad \text { requires nucleic acid purification } \\
\text { - } \quad \text { risk of contamination }\end{array}$ \\
\hline Microarray Analysis & 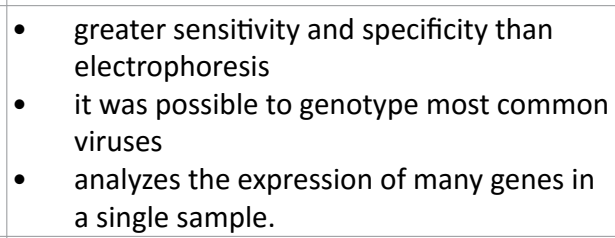 & $\begin{array}{ll}\text { - } & \text { requires nucleic acid purification } \\
\text { - } & \text { higher cost } \\
\text { - } & \text { possibility of cross-hybridization } \\
\text { - } & \text { risk of contamintation }\end{array}$ \\
\hline FTIR Spectroscopy & $\begin{array}{l}\text { - } \quad \text { Effective in differentiating malignant cervi- } \\
\text { - } \quad \text { It requires very few sample quantities. } \\
\text { - } \quad \text { greater precision } \\
\text { - } \quad \text { high performance } \\
\text { - } \quad \text { low workload for the cytologist } \\
\text { - tissue or cell culture } \\
\text { - noninvasive monitoring of biomolecules }\end{array}$ & $\begin{array}{l}\text { - } \quad \text { Complex data analysis in specific software } \\
\text { - } \quad \text { equipment of high cost of acquisition and } \\
\text { - Samples contaminated with blood, micro- } \\
\text { organisms and cellular debris can alter the } \\
\text { results and interpretations of the spectral } \\
\text { data. }\end{array}$ \\
\hline Ultrasensitive Biosensors & $\begin{array}{ll}\text { - } & \text { high sensitivity } \\
& \text { advantageous detection limit of DNA } \\
& \text { analysis } \\
\text { - } & \text { good selectivity }\end{array}$ & - does not distinguish high and low risk groups \\
\hline
\end{tabular}

Fonte: Coutlée et al, 2005; Sahu, Mordecai, 2005; Brandstetter et al, 2010; Arron et al, 2011; Camargo et al, 2011; Ostrowska et al, 2011; Wood Kiupel, McNaughton, 2014; Meisal et al, 2017; Rymsza et al, 2018. 
The microplate colorimetric hybridization assay (MCHA) is a method that enables the identification of six HR-HPV types $(16,18,31,33,39$ and 45$)$ by use of the GP5+/GP6+ primers, which amplify about 150 bp within L1 gene, followed by colorimetric hybridization with six type-specific probes on microwell plates. This technique compared with PapilloCheck $\AA$ technique, showed a significant agreement for HPV types 31,33, 45, greater sensitivity in identifying HPV 16/18, but poor agreement for $39^{31}$.

\section{Polymerase chain reaction techniques}

HPV-PCR (polymerase chain reaction) protocols use specific primers, especially MY09/MY11 and GP5+/GP6+ primers, which amplify conserved regions of the HPV genome, such as the L1 gene that allow the detection of the presence of $\mathrm{HPV}^{32}$. After amplification, HPV genotypes can be determined separately using techniques such as restriction fragment length polymorphism (PCR-RFLP), multiplex PCR, real time PCR (RT-qPCR), nucleic acid hybridization assays, direct sequencing, among others ${ }^{33}$. PCR techniques also have some disadvantages, leading to false negative results for multiple type infections contained in samples with lower copy numbers. Because of this problem, the PCR method may not detect all the HPV genotypes present in the sample ${ }^{34}$. Amplification of samples containing DNA from more than one HPV genotype may lead to a much stronger amplification of one of the sequences present, which would complicate the detection of all genotypes in a sample with multiple infections. Occasionally, intensive additional procedures such as sequencing or microarray techniques are needed to clarify the diagnosis.

The identification of viral types by PCR-RFLP, technique more affordable when compared to sequencing ${ }^{35}$, shows a satisfactory discriminatory power in differentiating viruses into $H R$ or $L R$, and it is possible to identify single or multiple infections. In this technique, the restriction enzymes BamHI, Dd6eI, HaeIII, HinfI, PstI or RsaI digest the amplified DNA, resulting in fragments of various lengths, facilitating the diagnosis of which type of HPV is present in the patient ${ }^{36}$.

Multiplex PCR, such as PapilloCheck $\AA$ assay, detects the genotypes of $24 \mathrm{HPV}$ types in a single reaction (HPV$6,11,16,18,31,33,35,39,40,42,43,44,45,51,52$, $53,55,56,58,59,66,68,70,73$ and 82 ). The assay uses fluorescent primers to amplify a $350 \mathrm{bp}$ fragment of the HPV E1 gene, comprising 28 probes, each at five replicate points fixed on a DNA chip ${ }^{37}$. Hybridization is performed using a microarray chip, which is automatically digitized and analyzed ${ }^{38}$. The main advantages of the PapilloCheck $\AA$ assay are the identification of HR/LR-HPV, the detection of multiple infections and be considered a fully reliable screening test. However, this assay does not amplify HPV types 35 and 53, the cost is relatively high and requires fully specific equipment ${ }^{39}$.

RT-qPCR technique is reliable, sensitive and specific diagnostic tool for the detection and genotyping of HPV types from tissue samples and cellular fluids ${ }^{40}$. This method has many advantages, such as the high capacity to detect viral load and the use of different fluorochromes that emit fluorescence. In addition, with this technique it is possible to obtain the amplification of different nucleic acid targets, being able to detect them even in very small concentrations $^{41}$. The clinical test COBAS $₫ 4800$ HPV test presents automated sample preparation combined with real-time PCR technology to detect 14 types of HR-HPV ${ }^{47}$ as a pooled result, all in one test and one patient sample ${ }^{42}$.

Although molecular methods have high specificity and sensitivity in the identification of several HPV genotypes in clinical samples, only the presence of viral DNA is not always associated with an active biological status of the virus, which justifies an analysis of the expression of E6 and E7 oncogenes and several genes associated with the regulation of cell cycle, as well the proteins expressed by these genes ${ }^{43}$. Two commercial trial based on multiplex RTqPCR, PreTect $®$ Proofer and APTIMA $®$ HPV Assay ${ }^{44}$, are the main techniques used to expression evaluation of the E6/ E7 genes, which can be specific markers for the diagnosis of HPV precancerous lesions ${ }^{45}$. For this reason, the search for E6/E7 transcripts could increase the specificity and sensitivity of screening tests for cervical lesions, that is more specific than HPV-PCR for the detection of HSIL (high-grade squamous intraepithelial lesions) ${ }^{28}$. PreTect $\AA$ Proofer has a high ability to detect five HR-HPV types (16, $18,31,33$ and 45 HPV types) ${ }^{28}$ and APTIMA® HPV assay has a greater sensitivity to detect 14 HR-HPV types $(16,18$, $31,33,35,39,45,51,52,56,58,59,66$ and 68$)^{46}$. These assays have several advantages over the other HPV tests and may be an excellent marker of cervical cancer.

\section{Microarray Analysis}

HPV can be genotyped quickly and reliably by PCRcoupled DNA microarray analysis. The HPV DNA chip showed greater sensitivity and specificity than gel electrophoresis and, in some cases, brought better results than direct DNA sequencing. In the study by Brandstetter et al., (2010) ${ }^{47}$ a chip designed with 36 probes was used to determine 12 common and different HPV genotypes. In this study, it was possible to genotype most common viruses that, according to current prevalence studies, covers 85$95 \%$ of all infections. Following this approach, only 10 copies of viruses can be detected within a short period of exposure $^{48}$.

Clinical Arrays $®$ HPV that allows the detection and genotyping ofHPV such as CLART $® H u m a n$ papillomavirus ${ }^{44}$ and Linear array ${ }^{49}$ use biotinylated primers that amplify a 
$450 \mathrm{bp}$ fragment within the L1 polymorphic region of the HPV genome. Amplicons are detected by hybridization in a low intensity microarray containing DNA probes specific for more than 35 HPV types including HR and LR in one assay. On the CLART methodology, the amplicons are detected by hybridization in a low intensity microarray containing triplicate DNA probes specific for 35 HPV types including HR and LR in one assay. The linear array allows discrimination of 36 types of HPV, 15 HR, 3 probable HR, 10 LR and 9 genotypes for which the risk is still uncertain ${ }^{49}$.

\section{Protein-based assay: Immunohistochemical analysis}

Protein-based assays are used to aid in the determination of diagnosis and prognosis in various types of cancer. In cervical cancer, the detection of altered expression in some proteins, such as p53, E6 and E7, may serve as an indirect marker for the presence of precancerous cervical lesion ${ }^{19}$. The immunohistochemical technique has been used to evaluate the expression of proteins in cervical cancer tissues and the influence of these organic compounds on carcinogenesis. Using this technique, Liu et al observed that the simultaneous detection of p53 and Ebp1 is associated with uterine cervix cancer $(\mathrm{p}<0.05)$ and may aid diagnosis, considering that Ebp1 is being positively regulated in this neoplasm, and both proteins may be potential biomarkers of this tumor ${ }^{50,51}$.

Although the detection of viral DNA is the only biomarker that makes it possible to diagnose cervical cancer, some proteins are being studied to aid diagnosis and to enable a more effective treatment. The cytokeratin serum fragments (CYFRA), carcinoma embryonic antigen (CEA), soluble CD44 (sCD44), squamous cell carcinoma antigen (SCC-Ag), matrix metalloproteinases (MMPs) and tissue inhibitors of metalloproteinases (TIMPs) are biomarkers based on biomolecules that have been identified as proteins that may help in diagnosis of cervical cancer ${ }^{52}$.

\section{FTIR Spectroscopy}

Fourier Transform Infrared Spectroscopy (FTIR) has been recognized as a non-destructive, stereotyped, highly sensitive and specific analytical method with useful applications in different fields of biomedical research and in research and diagnosis of cancer ${ }^{53}$.

In this infrared technique, a "cell biochemical impression" is engineered from integrated lipid molecules, as well as protein and carbohydrate composition, transformed into derivative in the form of a spectrum through vibrational transitions of individual chemical bonds of a single molecule ${ }^{54}$. The use of the FTIR has shown a very large capacity for the diagnosis of malignant cells and the diagnosis of cervical cancer has been much studied ${ }^{55}$. Ostrowska et al have shown the effectiveness of FTIR in differentiating malignant cervical cells and normal cells, as compared to the gold standard of histopathology, and the Principal Component Analysis (PCA) distinguished the groups of C33A, SiHa, HeLa and CaSki cell lines markedly by the characteristic cytoplasmic and nucleus signals of the cells ${ }^{56}$. Morris et al studied the spectral results of cervical cells using FTIR and observed remarkable distinctions in the most varied degrees of cellular differentiation of cervical intraepithelial neoplasia (CIN), revealing the capacity of this technology in the spectral differentiation of HPVpositive cervical lavage specimens ${ }^{57}$. In addition, the combination of the FTIR with the PCR methodology has been showing good results in the diagnosis of the HPV virus in cervical cancer ${ }^{4}$.

In developing countries, which have a higher incidence of cervical cancer compared to other countries, and do not have the financial resources to acquire reagents and materials needed for nucleic acid techniques, FTIR technology offers advantages because requires only an initial cost required for the acquisition of equipment and software for the analysis of spectral data. In this way, the FTIR presents a great potential to be used as an alternative or in conjunction with the current methods, with advantages such as greater precision, higher performance and lower workload for the cytologist or pathologist, besides having a greater accuracy and chance of early detection for the patient and identification of new diagnoses ${ }^{58}$.

\section{Ultrasensitive Biosensors}

Despite the applicability of several biochemical and molecular methodologies, the difficult in the distinction of the types of HPV present in clinical samples, as well as the high cost associated with the acquisition of equipment and reagents justify the development of new fast, cheap and specific technologies in the detection of HPV. With this in view, some studies have presented the use of electrochemical DNA biosensors as a promising technique of high sensitivity in signal amplification that requires reduced expenditures when compared with other techniques $^{59,60}$.

The central idea of this technology is based on the hybridization of the target DNA by probes that present $100 \%$ homology with the viral DNA in an immobilized substrate and has already been used in the differential diagnosis of the infection by high oncogenic risk genotypes, such as type 16 , which is characterized by being the main precursor of cervical cancer ${ }^{59,61}$. Furthermore, the detection of HPV DNA in human serum samples by biosensor can provides, in the future, a potential application in clinic research. However, the acquisition and manipulation of nanoparticles need a specific technical knowledge, and these biosensors are still in the study phase, which hinders their rapid application in clinical practice. 


\section{Conclusion}

Considering the increase in the number of cervical cancer cases worldwide and the need to detect HPV before cellular or histological changes become evident, it is important to study non-invasive, sensitive, specific and accessible diagnostic methods. For this, it is necessary to understand the performance of each biomarker associated with cervical carcinogenesis, contemplating the corresponding signaling pathways and their interaction with HPV infection.

\section{References}

1. Anon. Human papillomavirus vaccines: WHO position paper, May 2017-Recommendations. Vaccine. 2017; 35(43): 5753-5755.

2. Ferlay J, Soerjomataram I, Ervik M, et al. GLOBOCAN 2012 v1.0, Cancer Incidence and Mortality Worldwide: IARC CancerBase. No. 11 [Internet]. Lyon, Fr. Int. Agency Res. Cancer. 2013.

3. Huy NVQ Tam LM, Tram NVQ, et al. The value of visual inspection with acetic acid and Pap smear in cervical cancer screening program in low resource settings - A population-based study. Gynecol. Oncol. Reports. 2018; 24: 18-20.

4. Rymsza T, Ribeiro EA, de Carvalho LF das C e. S, et al. Human papillomavirus detection using PCR and ATR-FTIR for cervical cancer screening. Spectrochim. Acta - Part A Mol. Biomol. Spectrosc. 2018; 196: 238-246.

5. Traut H f, Papanicolaou GN. Cancer of the Uterus: the Vaginal Smear in Its Diagnosis. Cal. West. Med. 1943; 59(2): 121-122.

6. Koonmee S, Bychkov A, Shuangshoti S, et al. False-Negative Rate of Papanicolaou Testing: A National Survey from the Thai Society of Cytology. Acta Cytol. 2017; 61(6): 434-440.

7. World Health Organization. Human papillomavirus (HPV). WHO. 2013. Available from: http://www.who.int/immunization/topics/ hpv/en/

8. Burk RD, Harari A, Chen Z. Human papillomavirus genome variants. Virology. 2013; 445(1-2): 232-243.

9. Shukla S, Bharti AC, Mahata $S$, et al. Infection of human papillomaviruses in cancers of different human organ sites. Indian J. Med. Res. 2009; 130(3): 222-233.

10. Serravalle K, Levi JE, Oliveira C, et al. Comparação entre duas técnicas de genotipagem do HPV em mulheres com lesão intra-epitelial de alto grau. Rev. Bras. Ginecol. e Obs. 2015; 37(2): 94-99.

11. Schiffman M, Doorbar J, Wentzensen N, et al. Carcinogenic human papillomavirus infection. Nat Rev Dis Prim. 2016; 2: 1-20.

12. Oyervides-Muñoz MA, Pérez-Maya AA, Rodríguez-Gutiérrez HF, et al. Understanding the HPV integration and its progression to cervical cancer. Infect. Genet. Evol. 2018; 61(2017): 134-144.

13. Wang JW, Roden RBS. L2 , the minor capsid protein of papillomavirus. Virology. 2013; 445(1-2): 175-186.

14. Cruz-Gregorio A, Manzo-Merino J, Lizano M. Cellular redox, cancer and human papillomavirus. Virus Res. 2018; 246: 35-45.

15. Graham SV. The human papillomavirus replication cycle, and its links to cancer progression: a comprehensive review. Clin Sci. 2017; 131(17): 2201-2221.

16. Morshed K, Polz-Gruszka D, Szymañski M, et al. Human Papillomavirus (HPV) - Structure, epidemiology and pathogenesis. Otolaryngol Pol. 2014; 68(5): 213-219.

17. Tamarozzi ER, Giuliatti S. Understanding the role of intrinsic disorder of viral proteins in the oncogenicity of different types of HPV. Int J Mol Sci. 2018; 19(1): 1-15.

18. Miller AK, Munger K, Adler FR. A Mathematical Model of Cell Cycle Dysregulation Due to Human Papillomavirus Infection. Bull Math Biol. 2017; 79(7): 1564-1585.

19. Litwin TR, Clarke MA, Dean M, et al. Somatic host cell alterations in HPV carcinogenesis. Viruses. 2017; 9(8): 2-22.

20. Khoury R, Sauter S, Kovacic MB, et al. Risk of human papillomavirus infection in cancer-prone individuals: What we know. Viruses. 2018; 10(1): 2-15.

21. Aziz H, Iqbal H, Mahmood $\mathrm{H}$, et al. Human papillomavirus infection in females with normal cervical cytology: Genotyping and phylogenetic analysis among women in Punjab, Pakistan. Int J Infect Dis. 2018; 66: 83-89.

22. Harden ME, Munger K. Human papillomavirus molecular biology. Mutat Res Rev Mutat Res. 2017; 772: 3-12.

23. Bernard HU, Burk RD, Chen Z, et al. Classification of papillomaviruses (PVs) based on 189 PV types and proposal of taxonomic amendments. Virology. 2010; 401(1): 70-79.

24. Bzhalava D, Eklund C, Dillner J. International standardization and classification of human papillomavirus types. Virology. 2015; 476: 341-344.

25. Hammer A, Rositch A, Qeadan F, et al. Age-specific prevalence of HPV16/18 genotypes in cervical cancer: A systematic review and meta-analysis. Int J Cancer. 2016; 138(12): 2795-2803.

26. Zhao X, Wu Q Wang X, et al. The performance of human papillomavirus DNA detection with type 16/18 genotyping by hybrid capture in primary test of cervical cancer screening: A cross-sectional study in 10,669 Chinese women. Clin Microbiol Infect. 2018.

27. Coutlée F, Rouleau D, Ferenczy A, et al. The laboratory diagnosis of genital human papillomavirus infections. Can J Infect Dis Med Microbiol. 2005; 16(2): 83-91.

28. Hwang SJ, Shroyer KR. Biomarkers of cervical dysplasia and carcinoma. J Oncol. 2012: 1-9.

29. Arney A, Bennett KM. Molecular Diagnostics of Human Papillomavirus. Lab Med. 2010; 41(9): 523-530.

30. Johnson LR, Starkey CR, Palmer J, et al. A comparison of two methods to determine the presence of high-risk HPV cervical infections. Am J Clin Pathol. 2008; 130(3): 401-408.

31. Barcellos RB, Almeida SE de M, Sperhacke RD, et al. Evaluation of a novel microplate colorimetric hybridization genotyping assay for human papillomavirus. J Virol Methods. 2011; 177(1): 38-43.

32. Meisal R, Rounge TB, Christiansen IK, et al. HPV genotyping of modified general primer-amplicons is more analytically sensitive and specific by sequencing than by hybridization. PLoS One. 2017; 12(1).

33. Camargo M, Soto-De Leon S, Sanchez R, et al. Detection by PCR of human papillomavirus in Colombia: Comparison of $\mathrm{GP} 5+/ 6+$ and MY09/11 primer sets. J Virol Methods. 2011; 178(1-2): 68-74.

34. Okodo M, Okayama K, Teruya K, et al. Uniplex E6/ E7 PCR method detecting E6 or E7 genes in 39 human papillomavirus types. J Med Virol. 2018; (August 2017): 1-8.

35. Fateh A, Aghasadeghi M, Siadat SD, et al. Comparison of Three Different Methods for Detection of IL28 rs12979860 Polymorphisms as a Predictor of Treatment Outcome in Patients with Hepatitis C Virus. Osong Public Heal. Res Perspect. 2016; 7(2): 83-89.

36. Naqvi SH, Wajid S, Mitra AB. Restriction fragment length polymorphism of $\mathrm{L} 1$ amplicon using Rsa 1 detects five different human papillomavirus types and their co-infections among women 
attending a gynaecological outpatient department. J Virol Methods. 2004; 117(1): 91-95.

37. Heard I, Cuschieri K, Geraets DT, et al. Clinical and analytical performance of the PapilloCheck HPV-Screening assay using the VALGENT framework. J Clin Virol. 2016; 81: 6-11.

38. Pista A, Verdasca N, Oliveira A. Clinical performance of the CLART human papillomavirus 2 assay compared with the hybrid capture 2 test. J Med Virol. 2011; 83(2): 272-276.

39. Schopp B, Holz B, Zago M, et al. Evaluation of the performance of the novel PapilloCheck ${ }^{\circledR}$ HPV genotyping test by comparison with two other genotyping systems and the HC2 test. J Med Virol. 2010; 82(4): 605-615.

40. Moreau F, Fetouchi R, Micalessi I, et al. Detection and genotyping of human papillomavirus by real-time PCR assay. J Clin Virol. 2013; 56(3): 244-249.

41. Seo HH, Kim YJ, Jeong MS, et al. Combined SYBR Green realtime polymerase chain reaction and microarray method for the simultaneous determination of human papillomavirus loads and genotypes. 2016; 59(6): 489-497.

42. Iwasaki R, Galvez-Philpott F, Arias-Stella J, et al. Prevalence of highrisk human papillomavirus by cobas 4800 HPV test in urban Peru. Brazilian J Infect Dis. 2014; 18(5): 469-472.

43. Minami K, Kogashiwa Y, Ebihara Y, et al. Human papillomavirus and p16 protein expression as prognostic biomarkers in mobile tongue cancer. Acta Otolaryngol. 2017; 137(10): 1121-1126.

44. Cuschieri K, Wentzensen N. Human papillomavirus mRNA and p16 detection as biomarkers for the improved diagnosis of cervical neoplasia. Cancer Epidemiol Biomarkers Prev. 2008; 17(10): 25362545.

45. Litjens RJNTM, Hopman AHN, van de Vijver KK, et al. Molecular biomarkers in cervical cancer diagnosis: a critical appraisal. Expert Opin Med Diagn. 2013; 7(4): 365-77.

46. Dockter J, Schroder A, Eaton B, et al. Analytical characterization of the APTIMA® HPV Assay. J Clin Virol. 2009; 45(SUPPL. 1).

47. Brandstetter T, Böhmer S, Prucker O, et al. A polymer-based DNA biochip platform for human papilloma virus genotyping. J Virol Methods. 2010; 163(1): 40-48.

48. Arron ST, Skewes-Cox P, Do PH, et al. Validation of a Diagnostic Microarray for Human Papillomavirus: Coverage of 102 Genotypes. J Nucleic Acids. 2011; 2011: 1-6.
49. Dobec M, Bannwart F, Kilgus S, et al. Human papillomavirus infection among women with cytological abnormalities in Switzerland investigated by an automated linear array genotyping test. J Med Virol. 2011; 83(8): 1370-1376.

50. Liu L, Li X, Chen H, et al. Significance of Ebp1 and p53 protein expression in cervical cancer. Genet Mol Res. 2015; 14(4): 1186011866.

51. Liu L, Xu DY, Yang SS, et al. Ebp1 protein expression in cervical cancer tissue and its significance. Genet Mol Res. 2015; 14(2): 5496-5500.

52. Dasari S, Wudayagiri R, Valluru L. Cervical cancer: Biomarkers for diagnosis and treatment. Clin Chim Acta. 2015; 445: 7-11.

53. Bellisola G, Sorio C. Infrared spectroscopy and microscopy in cancer research and diagnosis. Am J Cancer Res. 2012; 2(1): 1-21.

54. Walsh MJ, German MJ, Singh M, et al. IR microspectroscopy: potential applications in cervical cancer screening. Cancer Lett. 2007; 246(12): 1-11.

55. Wood BR, Kiupel M, McNaughton D. Progress in Fourier Transform Infrared Spectroscopic Imaging Applied to Venereal Cancer Diagnosis. Vet Pathol. 2014; 51(1): 224-237.

56. 56. Ostrowska KM, Garcia A, Meade AD, et al. Correlation of p16 INK4A expression and HPV copy number with cellular FTIR spectroscopic signatures of cervical cancer cells. Analyst. 2011; 136(7): 1365-1373.

57. Morris BJ, Lee C, Nightingale BN, et al. Fourier transform infrared spectroscopy of dysplastic, papillomavirus-positive cervicovaginal lavage specimens. Gynecol Oncol. 1995; 56(2): 245-9.

58. Lyng FM, Traynor D, Ramos IRM, et al. Raman spectroscopy for screening and diagnosis of cervical cancer. Anal Bioanal Chem. 2015; 407(27): 8279-8289.

59. Campos-Ferreira DS, Nascimento GA, Souza EVM, et al. Electrochemical DNA biosensor for human papillomavirus 16 detection in real samples. Anal Chim Acta. 2013; 804: 258-263.

60. Huang H, Bai W, Dong C, et al. An ultrasensitive electrochemical DNA biosensor based on graphene/Au nanorod/polythionine for human papillomavirus DNA detection. Biosens Bioelectron. 2015; 68: 442446.

61. Machalek DA, Poynten M, Jin F, et al. Anal human papillomavirus infection and associated neoplastic lesions in men who have sex with men: A systematic review and meta-analysis. Lancet Oncol. 2012; 13(5): 487-500. 